\title{
Ethane-Selective Behavior Achieved on a Nickel-Based Metal-Organic Framework: Impact of Pore Effect and Hydrogen Bonds
}

\author{
Houxiao $\mathrm{Wu},{ }^{\mathrm{a}}$ Yongwei Chen, ${ }^{\mathrm{a}}$ Wenyuan Yang, ${ }^{\mathrm{b}}$ Daofei Lv, ${ }^{\mathrm{a}}$ Yinuo Yuan, ${ }^{\mathrm{a}}$

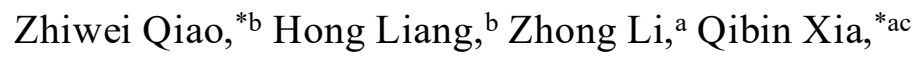 \\ ${ }^{a}$ School of Chemistry and Chemical Engineering, South China University of \\ Technology, Guangzhou 510640, P. R. China \\ ${ }^{b}$ Guangzhou Key Laboratory for New Energy and Green Catalysis, School of \\ Chemistry and Chemical Engineering, Guangzhou University, Guangzhou, \\ 510006, P. R. China
}

${ }^{c}$ Guangdong Provincial Key Lab of Green Chemical Product Technology, South China University of Technology, Guangzhou 510640, P.R. China

Synthesis of the MOF Ni-4PyC. The solvothermal synthesis of Ni-4PyC was carried out according to the literature report ${ }^{1}$. In a typical procedure, nickel carbonate $(0.119$ $\mathrm{g}, 1 \mathrm{mmol})$ and 4-PyC $(0.244 \mathrm{~g}, 2 \mathrm{mmol})$ were put into a $23 \mathrm{~mL}$ Teflon vial, and a mixture solution of $1.5 \mathrm{~mL}$ THF, $2 \mathrm{~mL} \mathrm{MeOH}$ and $2.5 \mathrm{~mL} \mathrm{H}{ }_{2} \mathrm{O}$ were added and the above mixture was under sonication for $5 \mathrm{~min}$. Then the Teflon vial was heated in an oven at $423 \mathrm{~K}$ for 72 hours. After cooling to room temperature, bright blue colored microcrystal product was collected by filtration and was washed with water and $\mathrm{MeOH}$ to remove the unreacted precursor. The solvent-exchange process was carried out by soaking the as-synthesized $\mathrm{Ni}-4 \mathrm{PyC}$ in $\mathrm{MeOH}$ for 3 days and was replaced 
with fresh $\mathrm{MeOH}$ every 8 hours. Then the solvent-exchanged Ni-4PyC was collected by filtration and dried at $423 \mathrm{~K}$ under vacuum for 10 hours.

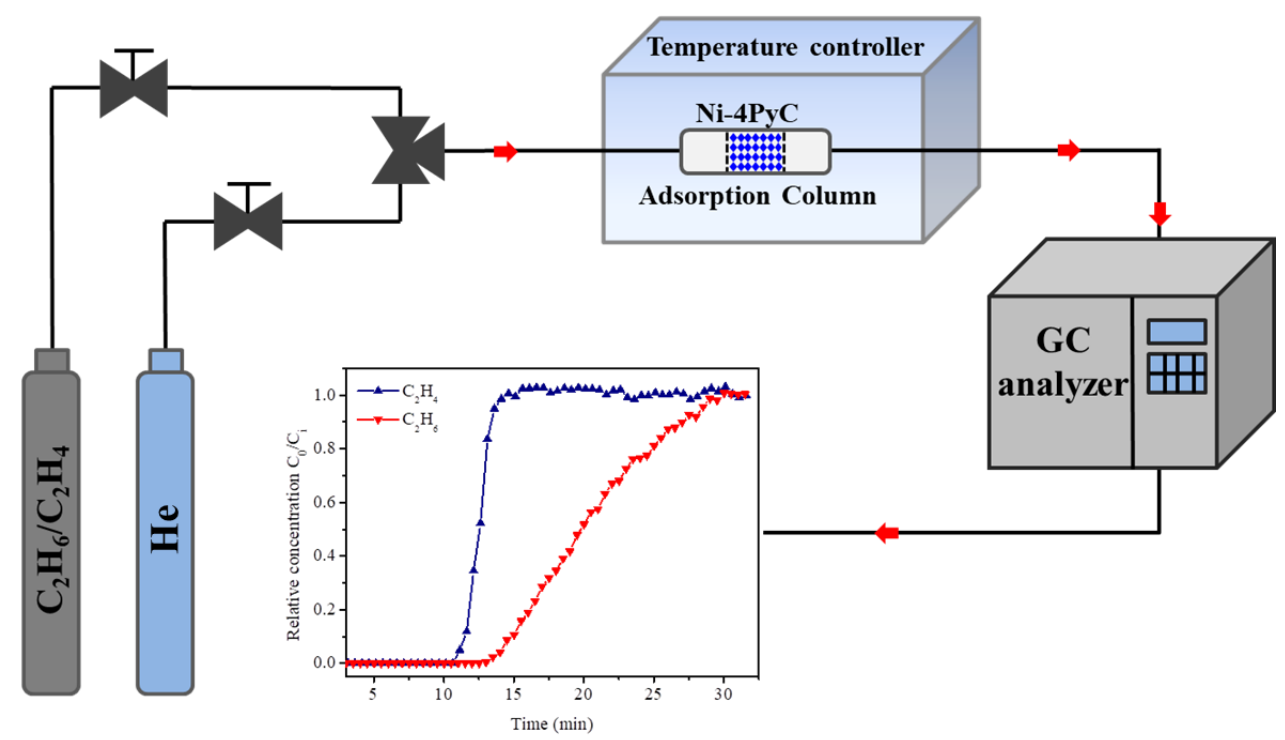

Scheme. S1. Schematic illustration of the apparatus used for breakthrough experiments.

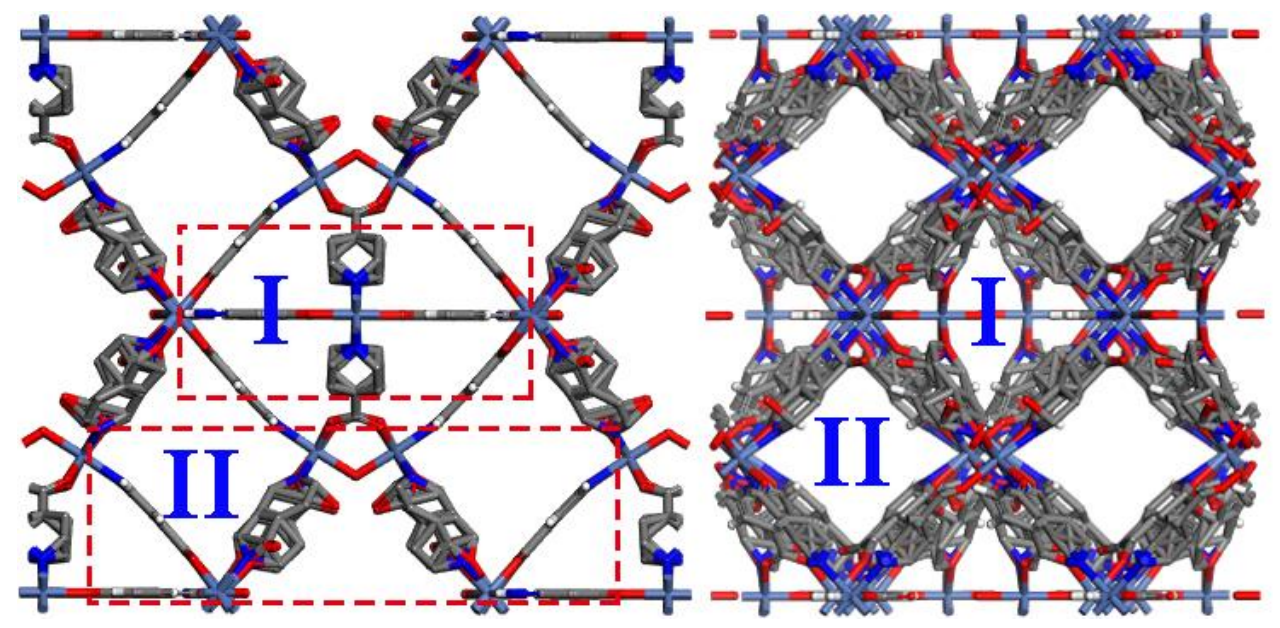

(a)

(b)

Figure S1. The guest-free framework $\mathrm{Ni}-4 \mathrm{PyC}$, viewed along and vertical to the $\mathrm{c}$ axis. 


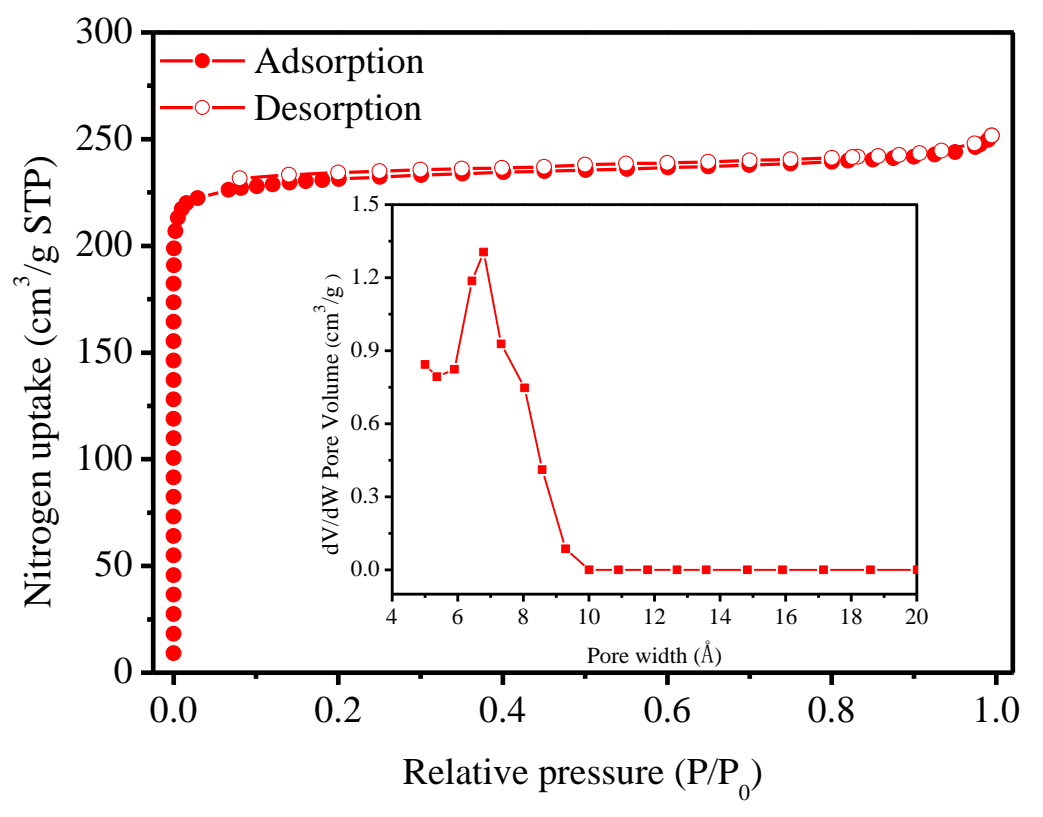

Figure S2. $\mathrm{N}_{2}$ adsorption-desorption isotherm of Ni-4PyC at $77 \mathrm{~K}$. The inset is the pore size distribution of Ni-4PyC.

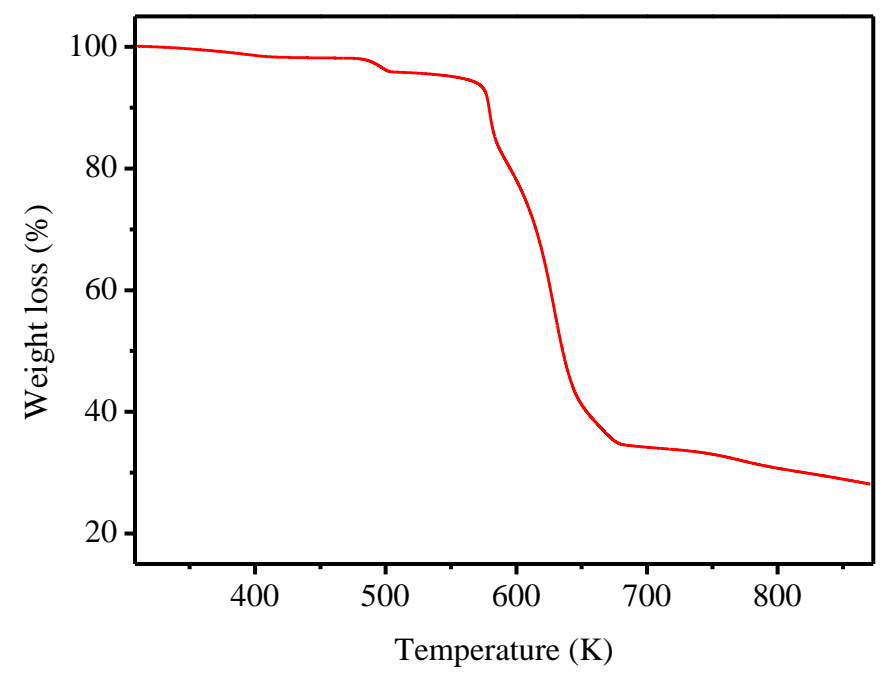

Figure S3. The TGA curve of Ni-4PyC 
Table S1. Lennard Jones parameters of Ni-4PyC

\begin{tabular}{cccccc}
\hline Atoms & $\mathrm{Ni}$ & $\mathrm{C}$ & $\mathrm{N}$ & $\mathrm{O}$ & $\mathrm{H}$ \\
\hline$\sigma(\AA)$ & 2.52 & 3.43 & 3.26 & 3.12 & 2.57 \\
$\varepsilon / k_{\mathrm{B}}(\mathrm{K})$ & 7.55 & 52.83 & 34.72 & 30.19 & 22.14 \\
\hline
\end{tabular}

Table S2. Comparisons of $\mathrm{C}_{2} \mathrm{H}_{6}$ and $\mathrm{C}_{2} \mathrm{H}_{4}$ adsorption uptakes and selectivity of $\mathrm{C}_{2} \mathrm{H}_{6} / \mathrm{C}_{2} \mathrm{H}_{4}$ in some $\mathrm{C}_{2} \mathrm{H}_{6}$-selective adsorbents at $100 \mathrm{kPa}$.

\begin{tabular}{cccccc}
\hline Adsorbents & $\begin{array}{c}\text { Temperature } \\
(\mathrm{K})\end{array}$ & $\begin{array}{c}\mathrm{C}_{2} \mathrm{H}_{6} \text { uptake } \\
(\mathrm{mmol} / \mathrm{g})\end{array}$ & $\begin{array}{c}\mathrm{C}_{2} \mathrm{H}_{4} \text { uptake } \\
(\mathrm{mmol} / \mathrm{g})\end{array}$ & $\begin{array}{c}\mathrm{C}_{2} \mathrm{H}_{6} / \mathrm{C}_{2} \mathrm{H}_{4} \\
\text { selectivity }\end{array}$ & Reference \\
\hline MAF-49 & 298 & 1.7 & 1.7 & 2.7 & {$[2]$} \\
IRMOF-8 & 298 & 3.6 & 2.8 & 1.8 & {$[3]$} \\
$\mathrm{Ni}(\mathrm{bdc})(\mathrm{ted})_{0.5}$ & 298 & 5.0 & 3.4 & 2.0 & {$[4]$} \\
$\mathrm{Cu}(\mathrm{Qc})_{2}$ & 298 & 1.85 & 0.78 & 3.4 & {$[5]$} \\
$\mathrm{MIL-142A}$ & 298 & 3.8 & 2.9 & 1.5 & {$[6]$} \\
PCN-250 & 298 & 5.2 & 4.2 & 1.9 & {$[7]$} \\
ZIF-7 & 298 & 2.0 & 1.9 & 2.5 & {$[8]$} \\
Ni-4PyC & 298 & 3.8 & 3.5 & 1.7 & This work \\
\hline
\end{tabular}

Table S3. Fitting parameters of the virial equation and the corresponding correlation coefficients

\begin{tabular}{ccccccccc}
\hline & $a_{0}$ & $a_{1}$ & $a_{2}$ & $a_{3}$ & $a_{4}$ & $b_{0}$ & $b_{1}$ & $R^{2}$ \\
\hline $\mathrm{C}_{2} \mathrm{H}_{6}$ & -3496.9 & -2.5192 & -0.0868 & $8.95 \mathrm{E}-4$ & $-1.85 \mathrm{E}-6$ & 11.18 & 0.0324 & 0.9999 \\
$\mathrm{C}_{2} \mathrm{H}_{4}$ & -3286.9 & -3.8424 & -0.0289 & $4.55 \mathrm{E}-4$ & -1.0651 & 11.21 & 0.0289 & 0.9999 \\
\hline
\end{tabular}

Table S1 presents the fitting parameters of the virial equation and the corresponding correlation coefficients $\left(\mathrm{R}^{2}\right)$. The values of $\mathrm{R}^{2}$ of all the fitting isotherms were up to 0.9999 , indicating that the adsorption isotherms of $\mathrm{C}_{2} \mathrm{H}_{6}$ and $\mathrm{C}_{2} \mathrm{H}_{4}$ on the Ni-4PyC can be well described by the virial equation. 


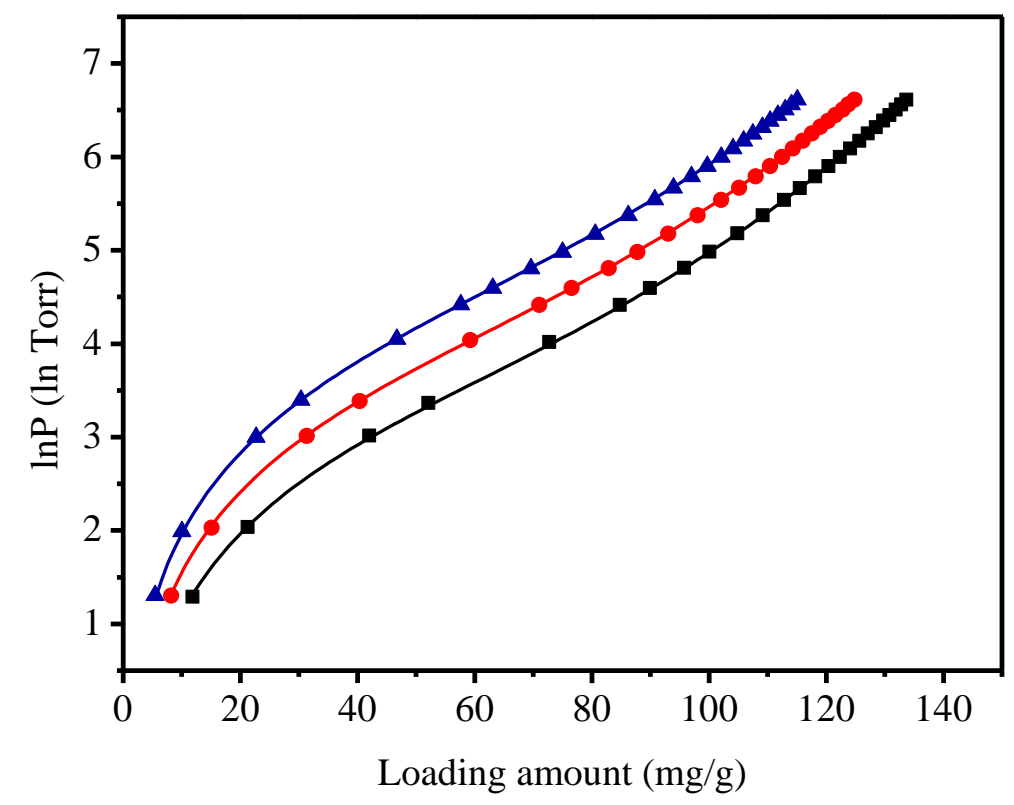

Figure S4. Virial fitting (lines) of $\mathrm{C}_{2} \mathrm{H}_{6}$ adsorption isotherms (points) of Ni-4PyC measured at 298 (blue), 288 (red), $273 \mathrm{~K}$ (black).

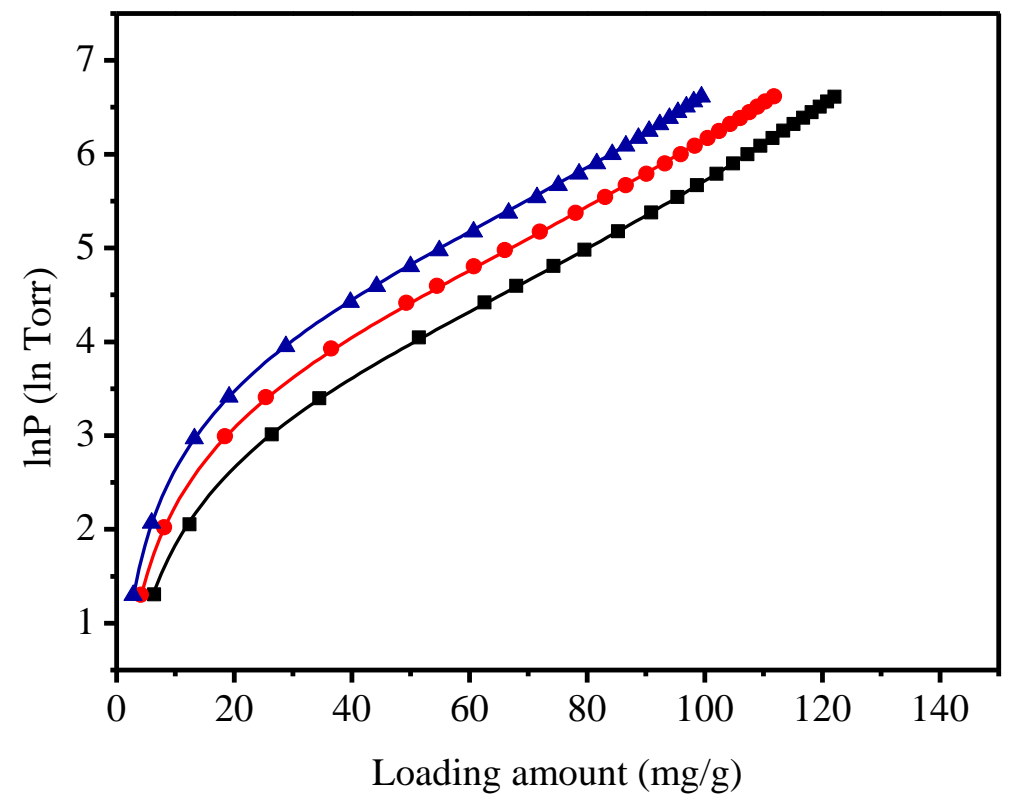

Figure S5. Virial fitting (lines) of $\mathrm{C}_{2} \mathrm{H}_{4}$ adsorption isotherms (points) of Ni-4PyC measured at 298 (blue), 288 (red), $273 \mathrm{~K}$ (black). 

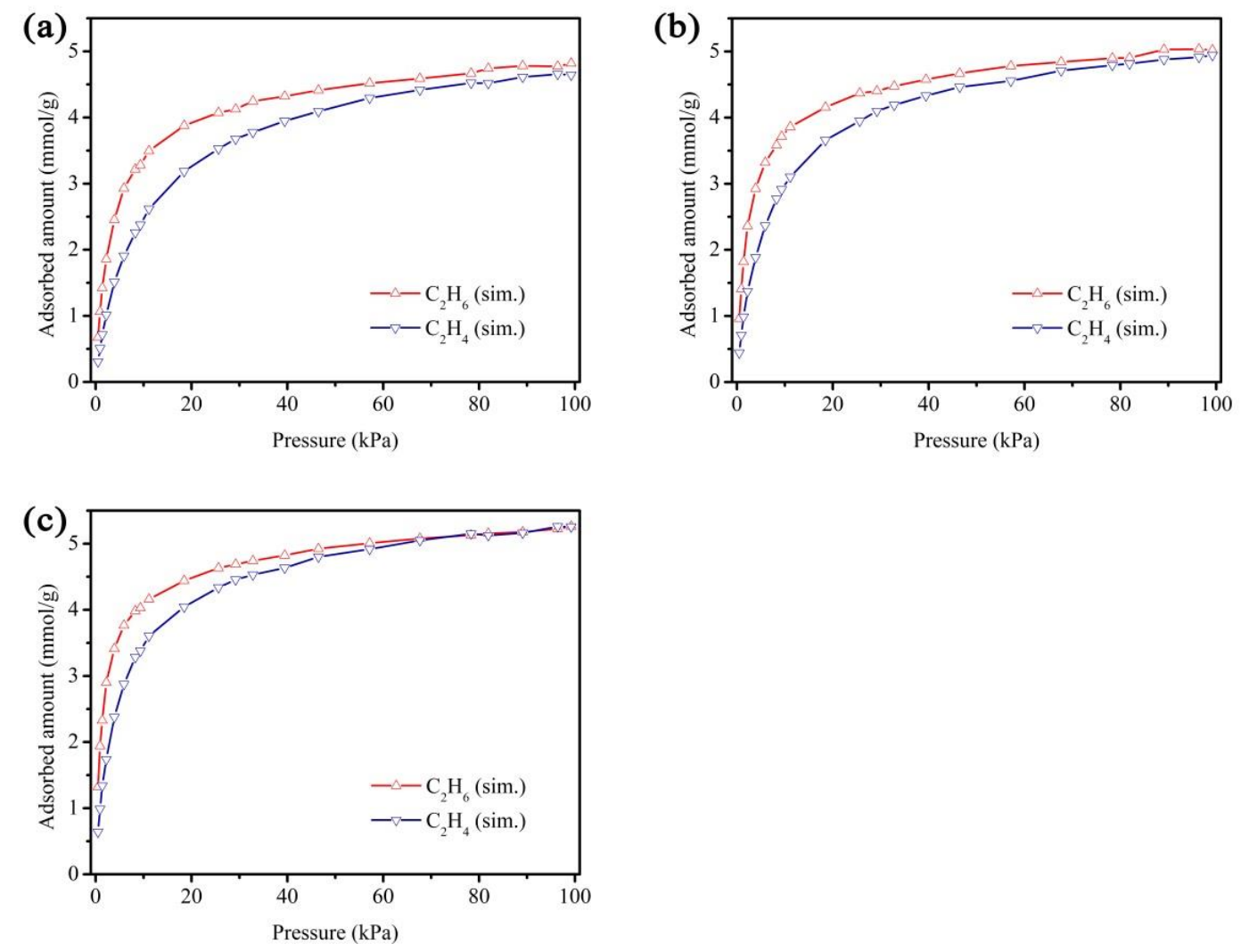

Figure S6. Computational simulated $\mathrm{C}_{2} \mathrm{H}_{6}$ and $\mathrm{C}_{2} \mathrm{H}_{4}$ adsorption isotherms on $\mathrm{Ni}-4 \mathrm{PyC}$ at (a) $298 \mathrm{~K}$, (b) $288 \mathrm{~K}$, (c) $278 \mathrm{~K}$

Table S4 Fitting parameters of the dual site Langmuir-Freundlich model

\begin{tabular}{cccccccc}
\hline Parameters & $\mathrm{q}_{\mathrm{m}, 1}$ & $\mathrm{~b}_{1}$ & $\mathrm{c}_{1}$ & $\mathrm{q}_{\mathrm{m}, 2}$ & $\mathrm{~b}_{2}$ & $\mathrm{c}_{2}$ & $\mathrm{R}^{2}$ \\
\hline $\mathrm{C}_{2} \mathrm{H}_{6}$ & 3.86393 & 0.08462 & 0.96217 & 2.67556 & 0.01388 & 0.57936 & 0.99998 \\
$\mathrm{C}_{2} \mathrm{H}_{4}$ & 3.56938 & 0.05587 & 0.97184 & 1.18526 & 0.00931 & 1.01084 & 0.99999 \\
\hline
\end{tabular}

The mathematical expression of DSLF model can be expressed as the following form:

$$
\mathrm{q}=q_{m, 1} \frac{b_{1} p^{c_{1}}}{1+b_{1} p^{c_{1}}}+q_{m, 2} \frac{b_{2} p^{c_{2}}}{1+b_{2} p^{c_{2}}}
$$

where $\mathrm{q}(\mathrm{mmol} / \mathrm{g})$ is the adsorbed amount for an adsorbent, $\mathrm{q}_{\mathrm{m}, 1}$ and $\mathrm{q}_{\mathrm{m}, 2}(\mathrm{mmol} / \mathrm{g})$ are the saturated adsorption capacities of site 1 and site $2, b_{1}$ and $b_{2}$ are the affinity coefficients for sites 1 and $2, \mathrm{p}(\mathrm{kPa})$ is the equilibrium pressure of the bulk gas, and 
$\mathrm{c}_{1}$ and $\mathrm{c}_{2}$ are the deviations from an ideal homogeneous surface. Both the pure component isotherms are well fitted by the model and the $\mathrm{R}^{2}$ values are larger than 0.9999 (see Table S3). To predict the adsorption selectivity, the fitting parameters of DSLF model were applied in the following equation:

$$
\mathrm{S}=\frac{\mathrm{x}_{1} / \mathrm{x}_{2}}{\mathrm{y}_{1} / \mathrm{y}_{2}}
$$

where $\mathrm{x}_{1}$ and $\mathrm{x}_{2}$ are the molar fraction of the adsorbed phase for component 1 and 2 , and $\mathrm{y}_{1}$ and $\mathrm{y}_{2}$ are the molar fraction of component 1 and 2 in the gas phase.

\section{References}

[1] Nandi, S.; Luna, P. D.; Daff, T. D.; Rother, J.; Liu, M.; Buchanan, W.; Hawari, A. I.; Woo, T. K.; Vaidhyanathan, R., A single-ligand ultra-microporous MOF for precombustion CO2capture and hydrogen purification. Science Advances 2015, 1 (11), e1500421-e1500421.

[2] Liao, P.-Q.; Zhang, W.-X.; Zhang, J.-P.; Chen, X.-M., Efficient purification of ethene by an ethane-trapping metal-organic framework. Nature Communications 2015, 6, 8697.

[3] Pires, J.; Pinto, M. L.; Saini, V. K., Ethane Selective IRMOF-8 and Its Significance in EthaneEthylene Separation by Adsorption. ACS Applied Materials \& Interfaces 2014, 6 (15), 12093-12099.

[4] Liang, W.; Xu, F.; Zhou, X.; Xiao, J.; Xia, Q.; Li, Y.; Li, Z., Ethane selective adsorbent $\mathrm{Ni}(\mathrm{bdc}$ (ted)0.5 with high uptake and its significance in adsorption separation of ethane and ethylene. Chemical Engineering Science 2016, 148, 275-281.

[5] Lin, R.-B.; Wu, H.; Li, L.; Tang, X.-L.; Li, Z.; Gao, J.; Cui, H.; Zhou, W.; Chen, B., Boosting Ethane/Ethylene Separation within Isoreticular Ultramicroporous Metal-Organic Frameworks. Journal of the American Chemical Society 2018, 140 (40), 12940-12946.

[6] Chen, Y.; Wu, H.; Lv, D.; Shi, R.; Chen, Y.; Xia, Q.; Li, Z., Highly Adsorptive Separation of Ethane/Ethylene by An Ethane-Selective MOF MIL-142A. Industrial \& Engineering Chemistry Research 2018, 57 (11), 4063-4069.

[7] Chen, Y.; Qiao, Z.; Wu, H.; Lv, D.; Shi, R.; Xia, Q.; Zhou, J.; Li, Z., An ethane-trapping MOF PCN-250 for highly selective adsorption of ethane over ethylene. Chemical Engineering Science 2018, $175,110-117$.

[8] Gücüyener, C.; van den Bergh, J.; Gascon, J.; Kapteijn, F., Ethane/Ethene Separation Turned on Its Head: Selective Ethane Adsorption on the Metal-Organic Framework ZIF-7 through a Gate-Opening Mechanism. Journal of the American Chemical Society 2010, 132 (50), 17704-17706. 